\title{
OSWALDOFILARIA SPP. (FILARIOIDEA, NEMATODA) \\ IN AUSTRALIAN AGAMID LIZARDS \\ WITH A DESCRIPTION OF A NEW SPECIES \\ AND A REDESCRIPTION OF \\ O. CHLAMYDOSAURI (BREINL)
}

\author{
R. MANZANELL
}

SUMMARY. Oswaldofilaria samfordensis n.sp. is described from Physignathus lesueurii and a redescription of $O$. chlamydosauri (Breinl, 1913) from Chlamydosaurus kingii and Amphibolurus barbatus is given. O. pflugfelderi (Frank, 1964) is confirmed as a valid species. A key is added to separate the four Australian species in the genus. Gonocephalus boydii was recorded as a new host for $O$. innisfailensis (Mackerras, 1962). A survey involving fifty specimens of $P$. lesueurii from South Queensland revealed that multiple infections with different filarioids are common and can include up to three different species in one individual animal. Pseudothamugadia physignathi (Johnston, 1912) (Splendidofilariinae) was the filarioid most frequently found, followed by $O$. samfordensis and $O$. pflugfelderi.

Oswaldofilaria spp. (Filarioidea, Nematoda) de Lézards d'Australie avec une description d'une nouvelle espèce et une redescription d'O. chlamydosauri (Breinl)

RÉSUMÉ. Oswaldofilaria samfordensis n.sp., parasite de Physignathus lesueurii, est décrite, et une redescription d'O. chlamydosauri (Breinl, 1913), parasite du Chlamydosaurus kingii, et d'Amphibolurus barbatus, est donnée. O. pflugfelderi (Frank, 1964), est confirmée comme espèce valide. Un tableau dichotomique est fourni pour séparer les quatre espèces australiennes du genre. Gonocephalus boydii est signalé comme nouvel hôte de $O$. innisfailensis (Mackerras, 1962). L'étude de $50 P$. lesueurii du Queensland du sud a révélé que des infections multiples à diverses filaires sont fréquentes. Trois espèces différentes peuvent être trouvées dans un seul animal. Ces filaires, de plus, se répartissent de la façon suivante, par ordre de fréquence décroissante : Pseudothamugadia physignathi (Johnston, 1912) (Splendidofilariinae), suivi d'O. samfordensis et $O$. pflugfelderi.

Department of Parasitology, University of Queensland, St. Lucia, 4067, Brisbane, Old. Australia. Accepté le $2 \mathrm{I}$ avril $\mathrm{r} 98 \mathrm{I}$. 


\section{Introduction}

According to Bain (1974) the genus Oswaldofilaria Travassos 1933 is represented in Australia by O. chlamydosauri (Breinl, 1913), O. innisfailensis (Mackerras, 1962) and $O$. pflugfelderi (Frank, 1964); all are parasites of agamid lizards. The available descriptions allow the differentiation of the females of these three species by the position of the vulva and the size of microfilariae. Corresponding males were not differentiated. This poses a problem because two of the three Australian Oswaldofilaria species can occur in the same individual host (Frank, 1964); furthermore a new species of Oswaldofilaria is described below from the same host as the one in which $O$. innisfailensis and $O$. pflugfelderi occur.

The occurrence of this fourth Australian species in the genus was anticipated in the literature by Mackerras (1962). This author noted the presence in bloodfilms of a stout and very small microfilaria, the adults of which were found in fragments only. Frank (1964) found O. pfugfelderi intermixed with "very long filarioids", which, as he mentioned, could be classified only with difficulty as $O$. innisfailensis, because of their greater length.

Sonin and Baruš (1968), on the basis of the available descriptions, suggested the synonymy of $O$. pflugfelder $i$ with $O$. chlamydosauri. A redescription of the latter species is therefore given below, to allow conclusions to be drawn.

\section{Materials and methods}

The agamid lizards examined were collected as road deaths or alive in their natural surroundings or obtained from various museum collections. Oswaldofilaria specimens were removed from membranes of the body cavity and muscle fascia. Specimens of Pseudothamugadia physignathi (Johnston, 1912) were found in the lumen of the portal vein.

\section{Material examined}

O. innisfailensis: Six males and five females; two males and two females from material of Mackerras, deposited in the Muséum national d'Histoire naturelle, Paris, two male and two female paratypes from Department of Parasitology, University of Queensland, the female type specimen (male not obtainable) from Queensland Museum and two specimens from own material: two males from Gonocephalus boydii, dissected in the Sydney Museum.

O. chlamydosauri: Eight males and forty-one females from Amphibolurus barbatus and five males and ten females from Chlamydosaurus kingii. One male and nine female specimens of former group from Mackerras' experimental infection (Mackerras, 1953). Two males and three females from O. chlamydosauri material from Mackerras 
(1953) from Aratula, South Queensland, in the Collection of the Department of Parasitology, University of Queensland. Two males and three females from the Australian Helminthological Collection, Adelaide (Lot 1540 from Chlamydosaurus kingii and Lot 1533 from Amphibolurus barbatus), identified by Johnston and Mawson (1943, p. 183). The remaining specimens were dissected from preserved Chlamydosaurus kingii from the Queensland Museum, Brisbane, the Zoological Museum of the University of Zurich and the Australian Museum in Sydney. The type material could not be found.

O. pflugfelderi: Seventeen males and twelve females type and allotype specimens from the Muséum national d'Histoire naturelle, Paris (No. 328G, type specimens: $326 \mathrm{G}, 327 \mathrm{G})$, fourteen males and seven females from own material from Physignathus lesueurii from Samford Valley, Brisbane, S.E. Queensland.

The fourth species: Twenty-six males and thirty-four females. Twenty-four males and thirty-one females from Physignathus lesueurii from Samford Valley, one female, labelled "Bobbin Head", New South Wales, from the Australian Museum (No. 17 156), and two males and two females from the Muséum national d'Histoire naturelle, Paris, deposited by Frank (1964), labelled as 'O. innisfailensis' (No. 336G).

Adult worms were observed alive in $0.75 \%$ saline under the microscope. After fixing in hot formalin ( $4 \%$ ) they were examined in chlorolactophenol, the clearing effect being controlled by adding small amounts of $70 \%$ alcohol. Some specimens were examined in pure glycerin. En face preparations and tail dissections were carried out and mounted in glycerin-jelly. Paraffin sections were made following standard techniques. Scanning electron microscope pictures were taken on a Cambridge Stereoscan 600, using alcohol or formalin as fixatives and critical point drying. Slides with stained bloodsmears of Physignathus lesueurii were obtained from the Muséum national d'Histoire naturelle, Paris, containing microfilariae of O. innisfailensis, O. pflugfelderi and the fourth Australian species (NI 219-NI 221, Frank [1964], p. 443) and from the Queensland Museum, Brisbane, containing microfilariae of $O$. innisfailensis (type material, G 2550). Many bloodsmears were made from naturally infected lizards with the microfilariae of $O$. chlamydosauri, O. pflugfelderi, Pseudothamugadia physignathi and of the new species described below.

Blood samples were taken from tail snippings, but as resulting wounds do not heal well with repeated blood sampling, the quicker and, for the animal, less disturbing method of sampling from the retro-orbital sinus was used, as described by MacLean et al. (1973). This bloodfilms were air dried, fixed with $100 \%$ ethanol and stained with Giemsa, Acid Mayers' Haematoxylin or Acetic Lacto-Orcein. Vital stains used include New Blue R, and Bleu de Meldola. 


\title{
Oswaldofilaria samfordensis $\mathrm{n}$. sp.
}

\author{
(Measurements in TABLE I)
}

TABLE I. - Body measurements of $O$. samfordensis and $O$. chlamydosauri (in $\mathrm{mm}$ )

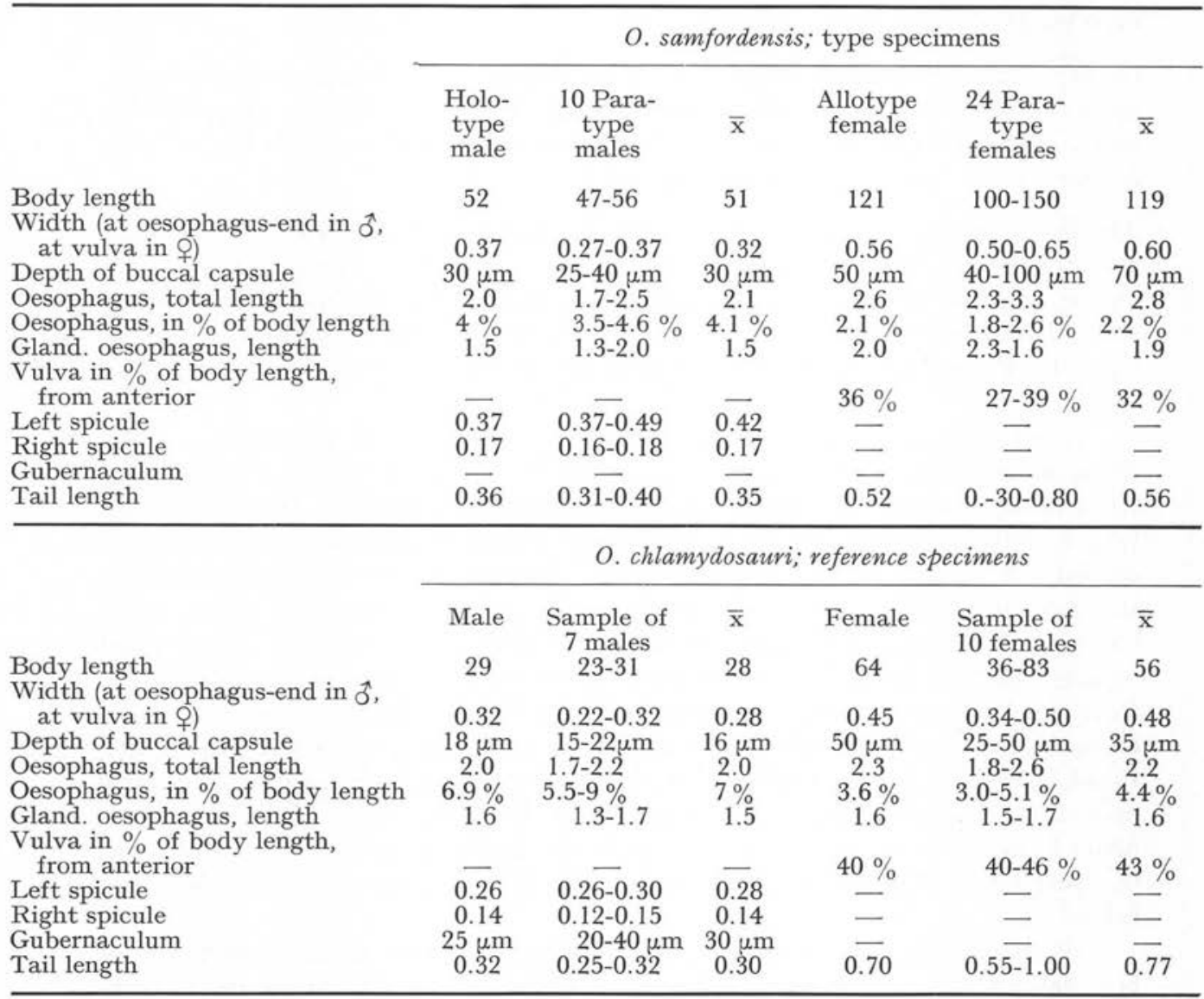

FIG. I. Oswaldofilaria samfordensis, male

a) Anterior end, lateral view with loose nerve ring and swelling of anterior intestine. Arrow indicates level of deirids ; b) Buccal capsule with cephalic muscle fibres ; c) Lateral view of posterior end with retractor of left spicule drawn in ; d) Left spicule, lateral view from right; e) Right spicule, ventro-lateral view : f) Tip of right spicule in dorso-lateral view ; g) Deirid, lateral view of worm-with lateral line underneath ; h) Deirid, dorso-ventral view of worm ; i, j) Ventral aspect of tail, showing variation of papillae distribution ; $1, \mathrm{k}, \mathrm{m}$ ) Cross-sections through the left spicule at anterior part of shaft, anterior tube opening and posterior part respectively.

( $a$ and $c$ to scale $500 \mu \mathrm{m} ; \mathrm{b}$, i and $\mathrm{j}$ to scale $100 \mu \mathrm{m} ; \mathrm{d}, \mathrm{e}, \mathrm{f}, \mathrm{g}, \mathrm{h}, \mathrm{k}, 1$, and $\mathrm{m}$ to scale $50 \mu \mathrm{m}$ ). 

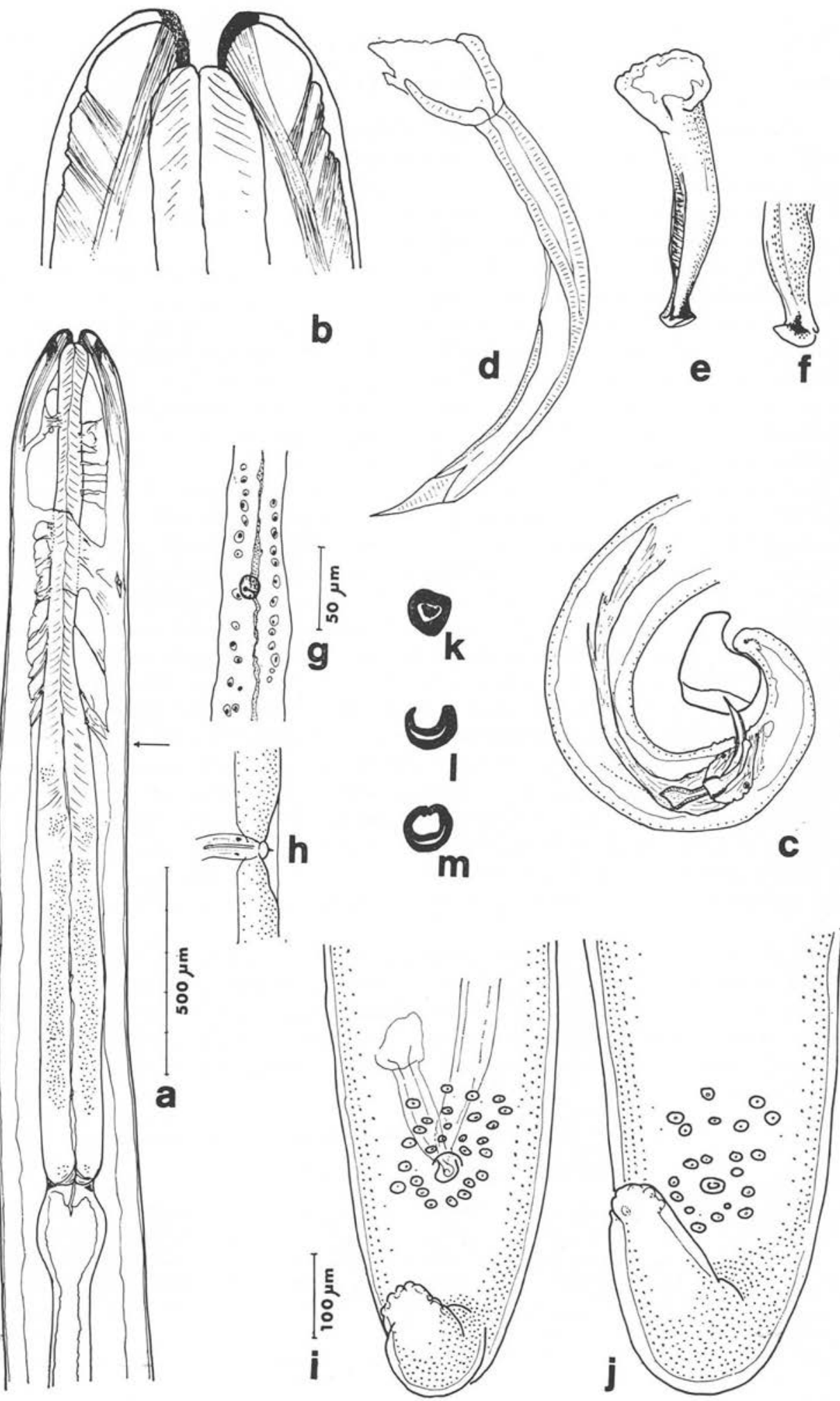
Opaque, white-yellowish filarioids. Cuticle finely striated. Ridges $3.5 \mu \mathrm{m}$ apart, towards both ends reduced to interrupted lines ( fig. 5), absent at tip of tail and at anterior end. Body cylindrical over nearly whole length. Anteriormost part tapers for $0.5 \mathrm{~mm}$ to an unevenly rounded head end. Cuticle around mouth opening thickened to prominent mouthplate (fig. 6).

Ten head papillae arranged as shown in figure $2 b$. Four cephalic papillae forming square around mouthplate (S.E.M. reveals, that each of them has central prominent cone on flat circular base, which shows several small openings of about $0.5 \mu \mathrm{m}$ in diameter). Four large smooth externolateral labial papillae form outline of laterally directed rectangle, each situated in niche in edge of mouthplate. Laterally inbetween them and also placed in a niche, are the two externomedian labial papillae. Amphids in form of a simple tube opening through cuticle just posterior to externomedian labial papillae. Deirids situated in both sexes at level of nerve ring or slightly posterior to it ( $f g .1 \mathrm{~g}, h ; 2 f, g$ ). Mouthplate of even width extending to buccal capsule. Buccal capsule nearly cylindrical with smooth walls (fig. $1 b, 2 a)$. Wall of buccal capsule adjacent to body parenchyma very rough in both sexes. Strongly developed muscle fibres insert at this point radiating outwards and backwards, bundled into eight symmetrical groups, posteriorly joining muscles of body wall (fig. 1b, 2a, c). Other cephalic muscle fibres inserted at rough outer margin of mouthplate in broad band, running posteriad to mix into the above-mentioned muscle fibres. Internal surface of mouthplate smooth between insertion areas. Oesophagus (fig. 1a, 2b) comprising anterior muscular part and posterior glandular part. Nerve ring loosely formed anterior to junction of muscular and glandular part of oesophagus. Oesophago-intestinal valve clearly formed, with lining continuous with duct of oesophagus ( fig. 2a). Intestine always enlarged at this junction, its diameter being bigger than diameter of glandular oesophagus. Particles inside intestine of both sexes include microfilariae and granular cells ( fig. 2a). Phasmids in both sexes opening through interstices of cuticular network, surrounded by seamlike cuticle fold ( fig. 7). Tip of tail marked with shallow circular groove.

Male: Posterior end of body coiled ventrally, tapering to rounded tip (fig. 1c). Spicules unequal and dissimilar ( $f i g .1 d, e, f$ ). Left spicule $0.8 \%$ of body length, right spicule about $41 \%$ of length of left one. Both spicules with strongly developed head. Anterior part of shaft cylindrical (fig. 1k), posterior part modified in both spicules. In left spicule shaft collapses towards posterior half to form channel,

FIG. 2. Oswaldofilaria samfordensis, female

a) Anterior end with cephalic muscles, loose nerve ring and swelling of anterior intestine, containing microfilariae; b) En face view with underlying cephalic muscle bundles in c; d) Vagina with common uterus and uterine bifurcation; e) Posterior end with uterus coiled around intestine; f) Deirid with cuticle-marking of lateral line; g) Deirid in dorso-lateral view of worm; h) Microfilaria with sheath, Giemsa stained; i) Microfilaria in vital stain, showing internal structures.

( $a$ and $d$ to same scale; $f$ and $g$ to same scale). 


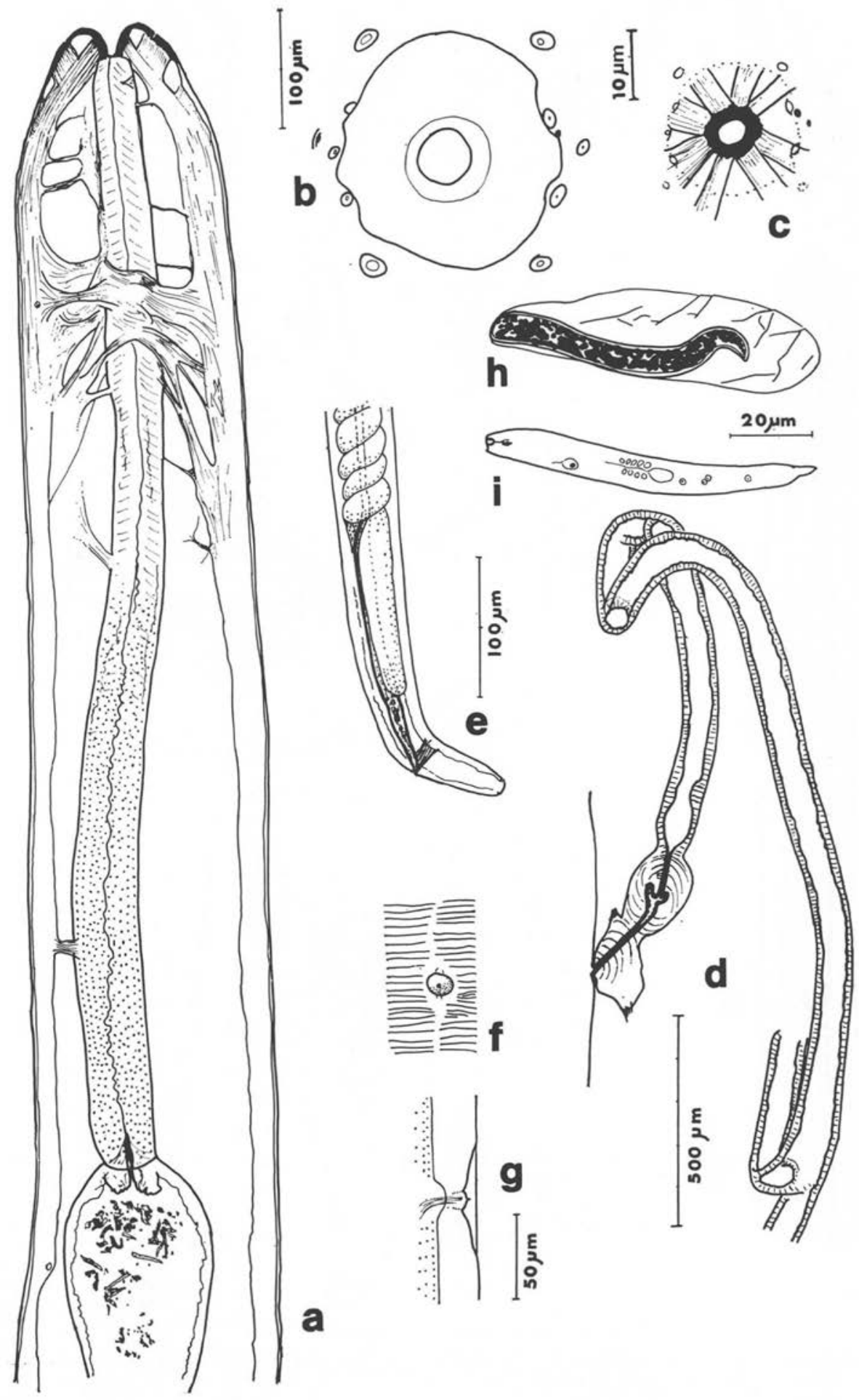



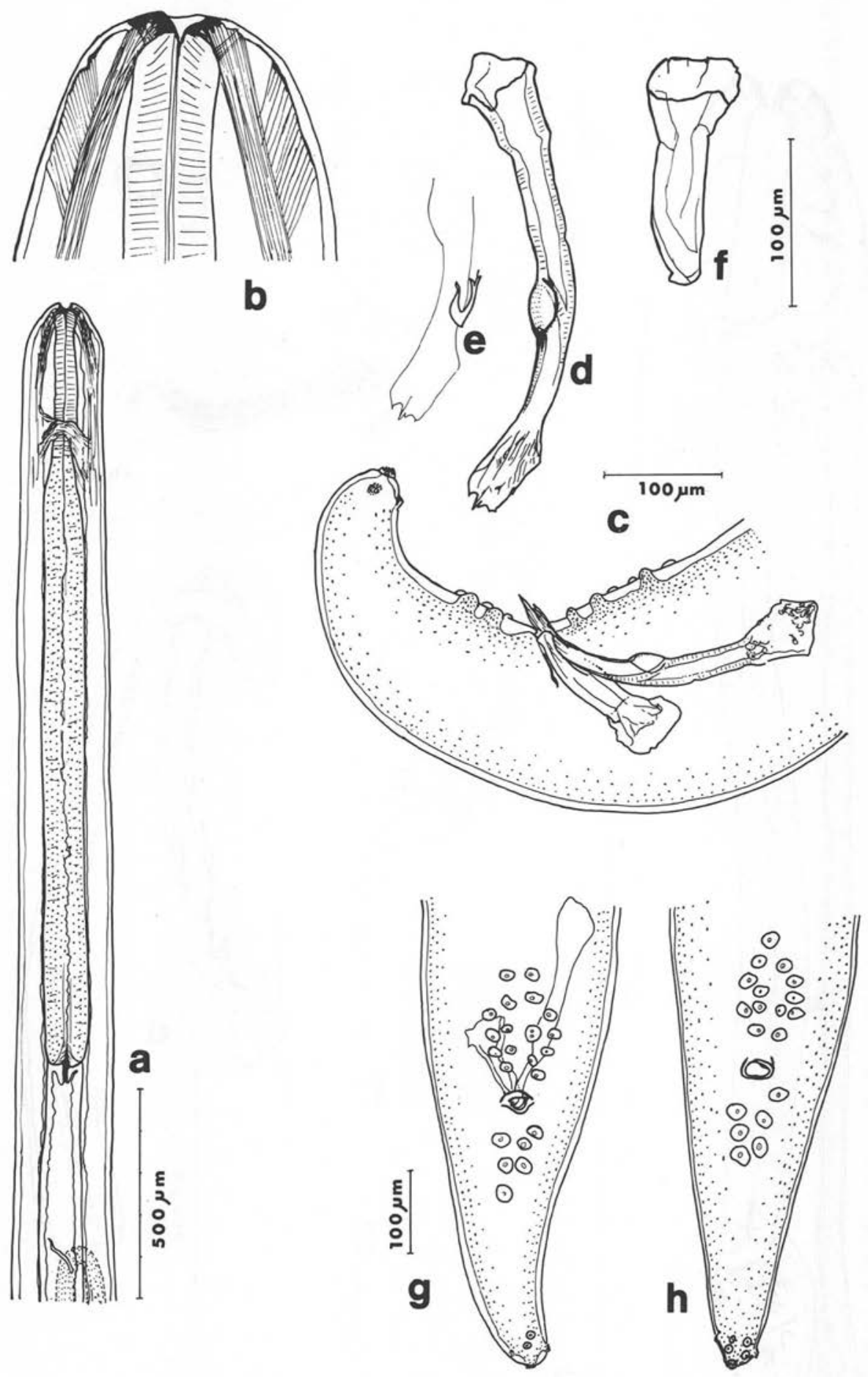

FIG. 3. Oswaldofilaria chlamydosauri, male

a) Anterior end. Note microfilaria in gut. Dotted lines indicate anterior most part of male genital tract; b) Buccal capsule in lateral view; c) Posterior end in lateral view with spicules and gubernaculum; d) Left spicule in right lateral view, with gubernaculum drawn in e ; f) Right spicule in right side view; $g, h$ ) Ventral view of tail, showing variation of papillae distribution. (b, $g$ and $h$ to scale roo $\mu \mathrm{m}$ of $g ; d$, e and $f$ to scale roo $\mu \mathrm{m}$ of $\mathrm{f}$ ). 


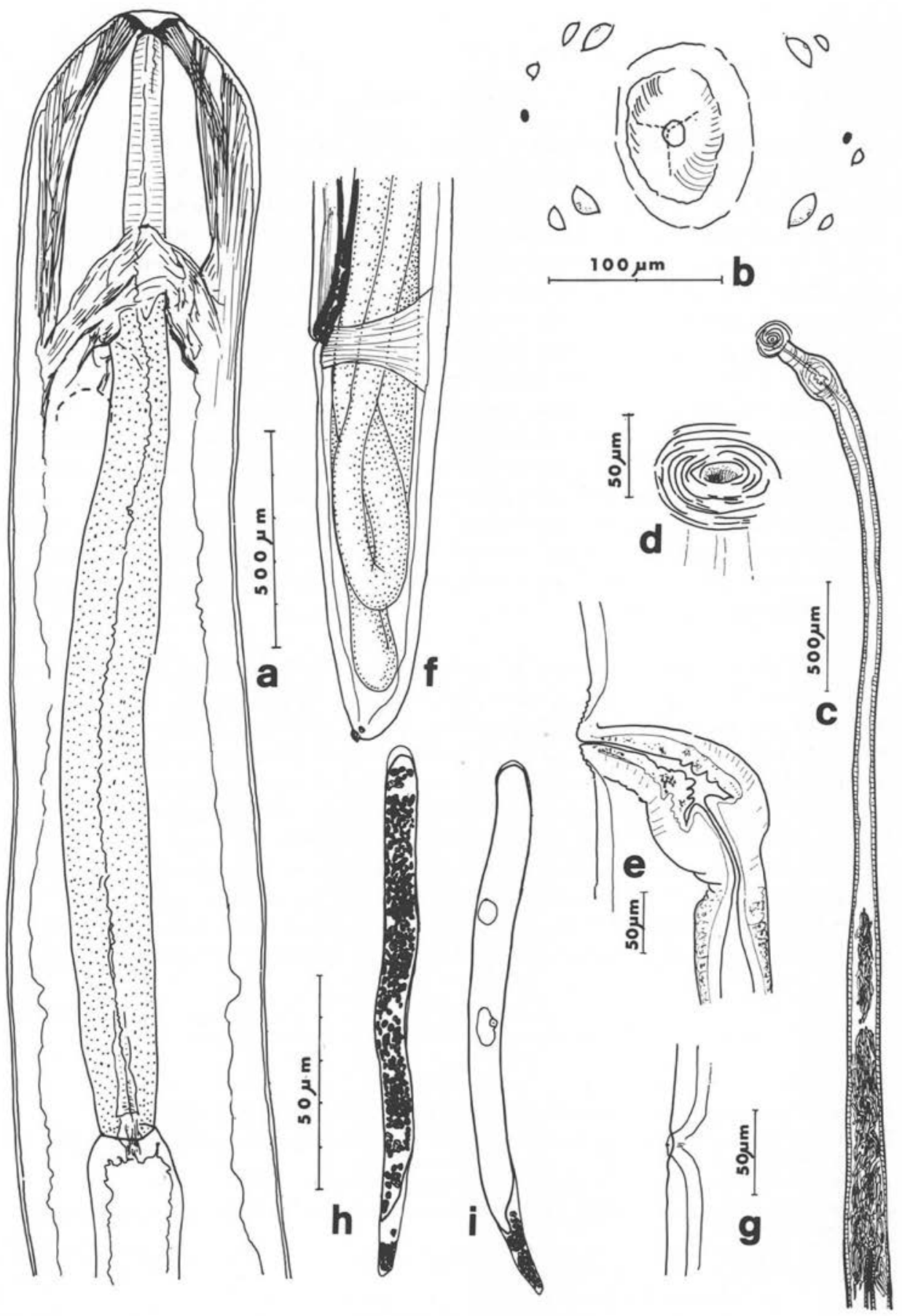

FIG. 4. Oswaldofilaria chlamydosauri, female

a) Anterior end with cephalic muscles and nerve ring. Dotted line indicates anterior most part of uterus; b) En face view ; c) Vagina with common uterus and uterus bifurcation; d) Vulva with concentric ridges on surrounding cuticle; e) Vagina, lateral view; f) Tail end with uterine coils and terminal denticles; g) Post deirid, as seen on one specimen $7 \mathrm{~mm}$ before tail end ; h) Microfilaria with sheath ,containing refractile granules, Giemsa stained,; i) Microfilaria vital stained, showing internal structures. 
with concave side facing ventrally. Lumen of core from here on reduced to narrow crescent $(f i g .1 \mathrm{~m})$. Sides of flattened spicule widening immediately after origin and bent ventrad ( fig. 1l). From point of contact posteriorly left spicule forming complete tube, with anterior opening just posterior to point where cylindrical shaft collapses and posterior opening just behind tip. Fine suture on spicule present on ventral side, where expanded spicule margins meet (fig. 9). Length of closed tube about $180 \mu \mathrm{m}$. Posterior half of shaft of right spicule gradually transforming to broad groove, starting as shallow depression on left side of shaft and gradually deepening posteriad and ventrad. Right spicule ends with bluntly rounded tip with end of groove on ventral side and with hook-shaped thickening on dorsal side ( fig. 8). Gubernaculum absent. Tail papillae large, one group pericloacal, one subterminal (fig. $1 i, j$ ); number of former group variable. Type specimen with 21 pericloacal papillae, other specimens with 18 to 27; anterior to cloaca papillae densely distributed in multiple and irregular rows, posterior to cloaca papillae distributed in more or less wedge-shaped pattern, pointing towards tail end. Subterminally two paires of papillae irregularely placed inbetween phasmids. Genital duct reflexed near oesophago-intestinal junction.

Female: Vulva at point one-third of body length from anterior end, not elevated, surrounding cuticle smooth. Vagina with muscular wall ( fig. 2d), average length 0.35-0.45 $\mu \mathrm{m}$, with strong muscles on either end. Cylindrical lumen dilated before muscular valve. Valve length about $0.1 \mathrm{~mm}$. Vagina and uterus running anteriad at first, then flexing back to bifurcation, where uterus separates into two branches after about $3.5 \mathrm{~mm}$. Unpaired section of uterus usually containing few microfilariae, paired sections normally filled with microfilariae. Uterine coils numerous, anteriormost reaching $1.4 \mathrm{~mm}(1.0-13.0 \mathrm{~mm})$ to front end, posteriormost coil $1.35 \mathrm{~mm}(0.8-$ $3.0 \mathrm{~mm}$ ) to tail end. Tail bent towards dorsal side (fig. $2 e$ ).

Microfilaria of. $O$. samfordensis (fig. $2 h, i$ ): Sheath always very loose and spacious, with wrinkles and folds, not containing refractile granules. Biggest diameter of

\section{PLANCHE I}

FIG. 5. - O. samfordensis; interrupted transversal ridges of cuticle near head end.

FIG. 6. - O. samfordensis; mouthplate of female in en face view, with papillae and amphid (A) arrowed on one side.

FrG. 7. - O. samfordensis; left phasmid on tail end in female.

FIG. 8. - O. samfordensis; right spicule protruding from cloaca with dorsal hook (arrow) and ventral groove.

FIG. 9. - O. samfordensis; left spicule protruding from cloaca (cl) with subapical opening of spicular tube (o) and ventral suture (s).

FIG. IO. - O. chlamydosauri; concentric ridges of cuticle around vulva.

FIG. II. - O. chlamydosauri; tail end in male with denticles on phasmid (ph) and on tip of tail $(\mathrm{t}) ; \mathrm{p}=$ papillae.

FIG. I2. - O. chlamydosauri; head of female in en face view. (Dorso-ventral plane of worm runs from left to right in the figure). 

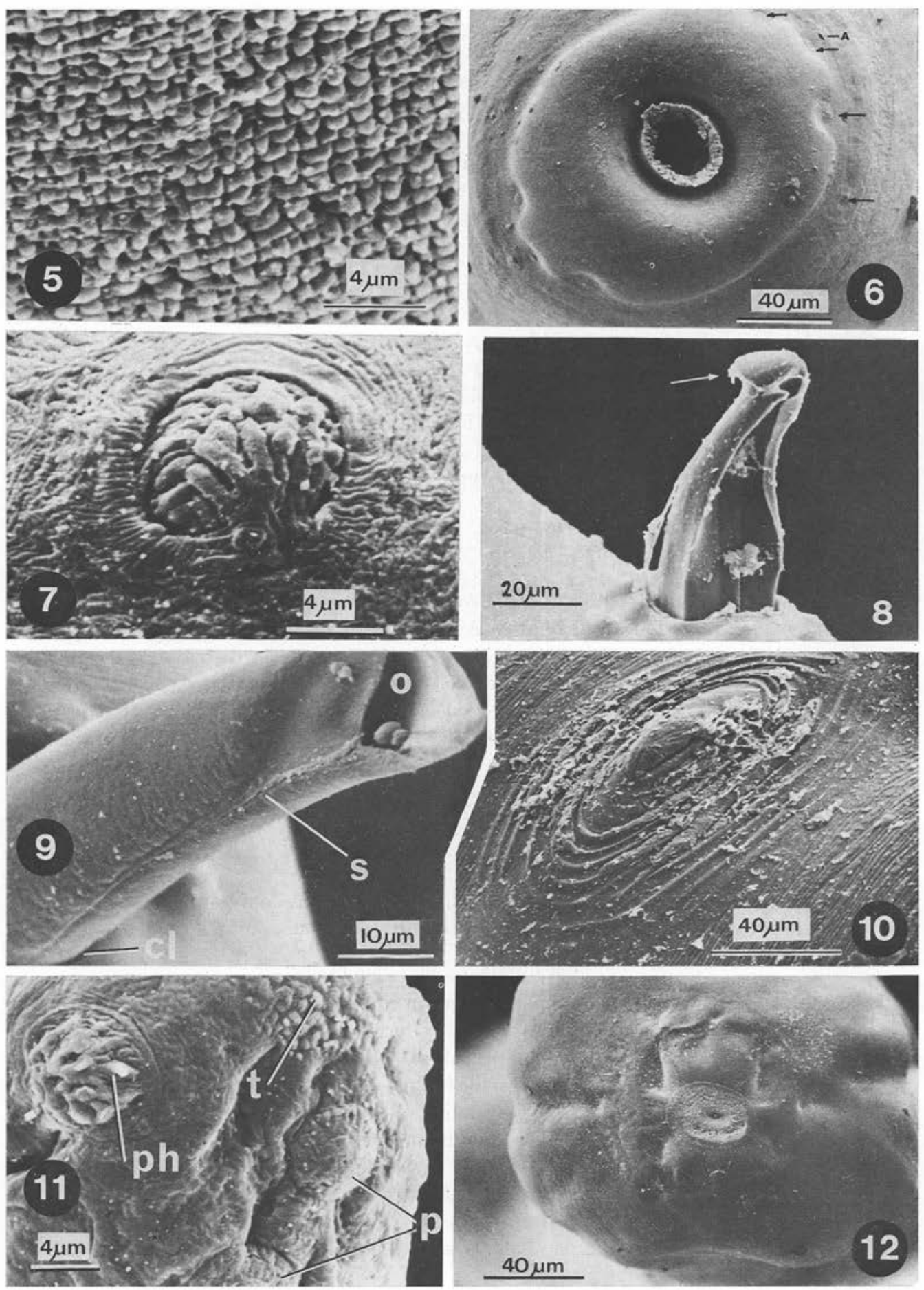
microfilaria near anterior end; posterior half tapering to slightly kinked tail. Cuticle finely striated. Cephalic hook and platelet hardly visible. Heat-fixed microfilariae $83 \mu \mathrm{m}$ long, $7.7 \mu \mathrm{m}$ wide in average. Excretory vesicle and Innenkoerper well visible, $20 \%$ and $55-60 \%$ respectively from anterior. Many refractile globules in entire body. Giemsa-stained microfilariae in thin bloodfilm $79 \mu \mathrm{m}$ long, $8.5 \mu \mathrm{m}$ wide; tail-end fully, head-end almost fully nucleated.

Type host : Physignathus lesueurii (Gray).

Other hosts : none known.

Type locality : South Pine River (Samford Valley) S.E. Queensland Australia.

Other localities: Gosford, near Sydney, New South Wales.

Site in host : Connective tissue layers and serous membranes of body cavity and muscle fascia of whole body. Microfilariae in fluids surrounding female worm, also in body cavity and blood.

Type material lodged in the Queensland Museum under following numbers:

$\begin{array}{ll}\text { Holotype and Allotype } & \text { G } 12659 \\ \text { Paratype males } & \text { G } 12660 \\ \text { Paratype females } & \text { G } 12661 \\ \text { Bloodfilms, 3 slides } & \text { G } 12662,3,4\end{array}$

Diagnosis: With characteristics of Oswaldofilaria Travassos, 1933, sensu Bain (1974). O. samfordensis is distinct from all other Australian species by the longer body length, left spicule forming tube ending in solid pointed tip, narrower distribution of pericloacal papillae, vulva at point onethird of body length from anterior, microfilariae smaller than $90 \mu \mathrm{m}$, enclosed in wide, loose sheath. In the last characteristic it differs from the Neotropical species too.

\section{Redescription of Oswaldofilaria chlamydosauri (Breinl)}

Synonyms: Filaria chlamydosauri Breinl, 1913.

Foleyella chlamydosauri (Breinl, 1913) Yorke \& Maplestone, 1926. Oswaldofilaria chlamydosauri (Breinl) Johnston \& Mawson 1943.

(Measurements in Table I)

Cuticle narrowly striated over whole length of body, smoothing out towards the two extremities. Four large and six smaller head papillae, distribution as shown in figure $4 b$. Amphids opening as simple tubes. No mouthplate developed. Buccal capsule (fig. 3b. 4a) laterally compressed, funnel-shaped, with strongly cuticularised walls. Thick bundles of muscle fibres leading outwards and backwards from nerve capsule, oesophagus with posterior glandular part wider than anterior muscular part. Nerve ring around posterior part of muscular œsophagus (fig. 3a, 4a), oesophago-intestinal junction with fleshy conical protruberance projecting into intestinal lumen, bearing cuticular lining of oesophagus. No deirids found in any specimen. In one female one deirid-like papilla was seen $7 \mathrm{~mm}$ from posterior end ( $f i g .4 b$ ). 
Phasmids large with coarse surface, similar in appearance to tip of tail, which is formed by group of small denticles within circular area. Both these structures are conspicuous and were present on all examined specimens (fig. $3 c, g, h, 4 f$ ).

Male: Anteriormost section of male genital tract extending to oesophago-intestinal junction. Posterior end of body strongly coiled ventrally, tail tapering to rounded tip (fig. 3c). Spicules unequal and dissimilar. Left spicule about $1 \%$ of body length. Shaft in anterior part cylindrical, flattening rapidly to distal third, margins covering over ventral side to form more or less closed tube with anterior opening. Towards posterior left spicule thinning out, tip being formed by fine membrane (fig. 3d). Right spicule stout, with groove starting on left side of shaft and deepening towards tip of spicule (fig. $3 f$ ). Outer rim of tip thickened. Gubernaculum 20-40 $\mu \mathrm{m}$ in length in a position about $40-20 \mu \mathrm{m}$ before cloacal opening ( $f i g .3 e, c$ ). Tail papillae relatively large, divided into two groups (fig. $3 g, h$ ). Cloacal group comprising 11-16 precloacal papillae, always arranged in multiple rows, and six further papillae just posterior to cloaca. A group of 4 subterminal papillae between two lateral phasmids.

Female: Head end evenly rounded, with mouthplate not prominent. Vulva in anterior half of body, raised, surrounded by several concentric cuticular ridges ( $f$ ig. 4d, 10). Vagina, $0.35 \mathrm{~mm}$ in length but variable, muscular, pear-shaped because of almost spherical sphincter muscle at junction with uterus ( $f i g .4 e$ ); narrow sphincter-duct measuring $0.12 \mathrm{~mm}$ in length. Internal vaginal walls smooth, with folds in vaginal chamber. Unpaired section of uterus $4 \mathrm{~mm}$ long in dissected female, at first running anteriorly then flexing posteriad to bifurcation. Tail straight sometimes containing uterine coils ( fig. $4 f$ ).

Examining all the available material from Mackerras (1953) it was found that all measurements lay within the range indicated above. The characteristic structures, especially the rough surface of the phasmids and the denticles on the tip of the tail, could be found in all specimens. The membraneous distal portion of the male's left spicule was clearly seen in all the specimens which were preserved with a protruded spicule.

Specimens originating from $A$. barbatus were compared with specimens from the type host $C$. kingii. No morphological difference was found except the slightly longer right spicule in relation to the left spicule, which in the $C$. kingii material measured $57 \%$ of the length of the left spicule, while the same percentage in the Amphibolurus barbatus material was $44-52 \%$

Microfilaria of $O$. chlamydosauri ( fig. $4 h, i$ ): Sheath tightly enclosing microfilaria laterally, part of sheath overhanging microfilaria at head, or more often tail end, containing many refractile granules.

Body nearly cylindrical, tapering in posterior third to fine blunt tail. Cuticle striated transversely. Heat fixed wet microfilariae 110 to $122 \mu \mathrm{m}$ in length by $6.5 \mu \mathrm{m}$ in width. Excretory vesicle at point $35 \%$ from head end. Few refractile 
globules in body. Haematoxylin stained microfilariae on thin bloodfilms measuring $110 \mu \mathrm{m}$ in length by $7.5 \mu \mathrm{m}$ in width. Anterior end containing five nuclei plus one larger nucleus, staining more lightly in Mayers Haematoxylin. These nuclei separated from rest of nuclear column by nuclear free band, $8 \mu \mathrm{m}$ far from anterior end. Group of six nuclei in tail set off from rest of body nuclei by nucleus-free band, $12 \mu \mathrm{m}$ from tail end. Another nuclear-free band at place of nerve ring, at a point $26 \%$ of body length from anterior end.

Type host : Chlamydosaurus kingii (Gray).

Other hosts : Amphibolurus barbatus (Cuvier).

Type locality : 'North Queensland' (Breinl, A., 1913).

Other localities: Eidsvold (Johnston and Mawson, 1943), Aratula (Mackerras collection), Inglewood (Mackerras, 1953). Specimens from this redescription are from Boonah and Clermont.

All localities in eastern Queensland.

Site in host : Connective tissue layers and serous membranes of body cavity and muscle fascia of whole body. Microfilaria in the blood.

Comment : Amphibolurus muricatus was mentioned as a host for this species by Johnston and Mawson (1943) from 'Burnett River', but as the material could not be found, this host record is not listed here.

Diagnosis: Oswaldofilaria Travassos, 1933, sensu Bain (1974). O. chlamydosauri is distinct from all other Australian species in the genus by the left spicule thinning out to a fine membraneous tip, denticles on phasmid openings and tip of tail, vulva in position just anterior to equator, and microfilariae 110-122 $\mu \mathrm{m}$ long in tight sheath. O. spinosa Bain, 1974, is reported to have similar denticles on the area of the phasmids. O. chlamydosauri differs from this neotropical species by the morphology of the spicules, the arrangement of tail papillae and longer microfilariae.

Development: A summary of all experiments done is published by Mackerras (1953). Development occurred in Culex fatigans and $C$. annulirostris.

Reference material: Queensland Museum, Brisbane, G 17665, 4 males; G 12666, 4 females; G 12667 and G 12668, bloodfilms.

\section{Survey of filaroids of Physignathus lesueurii in southern Queensland}

Physignathus lesueurii is distributed along the eastern coast of Australia. The specimens of this study were collected in south Queensland, the geographical middle of the range. Fifty adult $P$. lesueurii were dissected and/or examined for microfilaraemia in the years 1978 to 1980 . Thirty-five of them were found positive for any one or combinations of three different species of filarioids. The results are shown in table II. It is of special interest, that multiple infections were common and that 
single infections were always caused by Pseudothamugadia physignathi. All noninfected lizards originated from creeks and rivers under tidal influence, single infections from further upstream, where tidal variations were negligible, and 15 out of 16 lizards examined from an inland creek showed multiple infections.

TABLE II. - Occurence of filarioids in Physignathus lesueurii in southern Queensland

\begin{tabular}{|c|c|c|c|c|c|}
\hline Type of infection & $\begin{array}{l}\text { Number of } \\
\text { lizards }\end{array}$ & $\begin{array}{l}\text { P. physi- } \\
\text { gnathi }\end{array}$ & $\begin{array}{l}\text { O. samfor- } \\
\text { densis }\end{array}$ & $\begin{array}{l}\text { O. pflug- } \\
\text { felderi }\end{array}$ & $\begin{array}{l}\text { O. innisfai- } \\
\text { lensis }\end{array}$ \\
\hline No infection & 15 & 一 & - & 一 & - \\
\hline Single infection & 20 & $*$ & - & 一 & 一 \\
\hline & 7 & $*$ & $*$ & - & - \\
\hline Double infection & $10\left\{\begin{array}{l}2 \\
1\end{array}\right.$ & * & $\bar{*}$ & * & 二 \\
\hline Triple infection & 5 & * & * & * & - \\
\hline
\end{tabular}

The data about the geographical distribution so far available revealed an allopatric distribution: O. innisfailensis occured in the northern half of the range of distribution of Physignathus lesueurii with the southernmost locality of Innisfail; $O$. pflugfelderi and $O$. samfordensis were found in the southern half of the range, with Burnett River ( $400 \mathrm{~km}$ north of Brisbane) and Brisbane as the northernmost localities respectively.

Gonocephalus boydii (McLean) was found to be another host of $O$. innisfailensis. The range of distribution of this lizard overlaps with the north of the range of $P$. lesueurii in the Cape York Peninsula, North Queensland (J. Covacevich, Queensland Museum; pers. comm.).

\section{Discussion}

As three Oswaldofilaria spp. may occur in the same individual host, a key is provided to identify single male or female specimens of the four Australian spp. The key also reveals that $O$. pflugfelderi can be upheld as a separate species, in disagreement with the proposal of Sonin und Baruš (1968), who suggested that $O$. pflugfelderi is a synonym of $O$. chlamydosauri. A peculiarity of $O$. samfordensis is the transformation of the posterior part of the left spicule to a complete tube. The right spicule of the same species is shown on figure 8 in a protruded position, bearing the tip of the only slightly protruded left spicule in its groove. This intimate contact between the two spicules introduces the possibility that the right spicule functions as a gubernaculum for the left spicule. 
The above descriptions in conjunction with those given by Mackerras (1962), Frank (1964), Prod'hon and Bain (1972), Bain (1974) and Bain and Sulahian (1974) suggest that there is no continuous morphological characteristic separating the Neotropical spp. from the Australian spp. This points towards the close affinity of the two geographically separated groups which might not be structurally very different from the common ancestral forms.

\section{Key to Australian Oswaldofilaria species}

1 - Tailend with conspicuous denticularization within confined circular area, denticles on phasmids; gubernaculum present 25-30 $\mu \mathrm{m}$ long; vulva at point $43 \%(40-46 \%)$ of body length from anterior, surrounded by concentric cuticular ridges. Microfilariae $110 \mu \mathrm{m}$ long (dry bloodfilm), sheath tight, tubular $\ldots \ldots \ldots \ldots \ldots \ldots \ldots \ldots \ldots \ldots \ldots$ O. chlamydosauri

$1^{\prime}$ - Tailend and phasmids with smooth surface, gubernaculum absent; vulva further anterior, surrounding cuticle smooth. Microfilariae

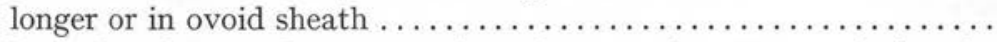

2 - Body length more than $40 \mathrm{~mm}$ in male, more than $100 \mathrm{~mm}$ in female, cephalic region heavily muscularized, strongly expressed cephalic plate, oesophagus cylindrical at anterior end, oesophagus length less than $5 \%$ of body length in male, distal portion of left spicule forming tube, tip solid; vulva at point $32 \%(27-39 \%)$ of body length from anterior; microfilariae $79 \mu \mathrm{m}$ long (dry bloodfilm), sheath ovoid, not containing refractile granules $\ldots \ldots \ldots \ldots \ldots \ldots \ldots \ldots \ldots \ldots$ O. samfordensis

$2^{\prime}$ - Body length less than $35 \mathrm{~mm}$ in male, less than $95 \mathrm{~mm}$ in female; cephalic region with only single muscle fibres; cephalic plate not strongly cuticularized; oesophagus anteriorly slightly swollen; oesophagus length more than $6 \%$ of body length in male, tip of left spicule thinning out to membrane; place of vulva as stated below; microfilariae longer than $130 \mu \mathrm{m}$, sheath tight, tubular, containing refractile

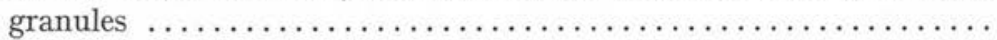

3 - Precloacal papillae arranged in two rows, midventrally, each row containing 4 to 5 papillae; vulva at point $29 \%(23-38 \%)$ from anterior, microfilariae $150 \mu \mathrm{m}$ long (dry bloodfilm) ............. O. pflugfelderi

$3^{\prime}$ - Precloacal papillae in multiple rows, 10 to 18 papillae; vulva at point $6 \%(5-9 \%)$ from anterior, microfilariae $126 \mu \mathrm{m}$ long (dry bloodfilm)

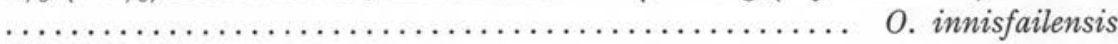

ACKNowledgements: The writer's thanks are due to Dr. O. Bain (Muséum national d'Histoire naturelle, Paris) for valuable discussions and for the loan of specimens; thanks are further extended to Dr. L. Cannon (Queensland Museum, Brisbane), to Dr. P. M. Thomas (University of Adelaide, Adelaide) and to Dr. P. Hutchings (Australian Museum, Sydney) for sending specimens of their collections, to Prof. V. Zis- 
wiler (Zoological Museum, University of Zurich), Miss J. Covacevich (Queensland Museum, Brisbane) and Dr. A. Greer (Australian Museum, Sydney) for providing me access to their reptile collections. Thanks are also due to $\mathrm{Mr}$. T. Hamley (Zoological Department, University of Queensland) for allowing me to sample several of his reptiles and to Mr. J. V. Hardy and Mr. R. W. C. Grimmer for producing S.E.M. pictures. To Prof. J. F. A. Sprent I am endebted for his guidance throughout this work. The author was supported by a University of Queensland Scholarship, which is gratefully acknowledged.

\section{REFERENCES}

Barn O. : Description de nouvelles filaires Oswaldofilariinae de lézards sud-américains ; hypothèse sur l'évolution des filaires de Reptiles. Bull. Mus. natn. Hist. Nat. Paris, $3^{\mathrm{e}}$ sér., no 208, Zool. $1974,138,169-200$.

Bain O., Sulahian A. : Trois nouvelles filaires du genre Oswaldofilaria chez des lézards sud-américains; essai de classification des Oswaldofilariinae. Bull. Mus. natn. Hist. Nat., Paris, $3^{e}$ sér., no 232 , Zool. I974, Is6, 827-841.

BREINL A : Nematodes observed in north Queensland. Report for I9I1. Australian Inst. Trop. Med. I913, 39-46.

Frank W. : Neubeschreibung einer Filarie, Macdonaldius pfugfelderi n. spec. (Nematoden, Filarioidea) aus der Muskulatur der Wasseragame, Physignathus lesueurii (Gray) (Reptilia, Agamidae). $Z$. f. Parasitenkunde, 1964, 24, 442-452.

Johnston T. H., Mawson P. M. : Remarks on some Nematodes from Australian Reptiles. Trans. Roy. Soc. S. Austr. 1943, 67, 183-186.

MACKERRAS J. M. : Lizard filaria : transmission by mosquitoes of Oswaldofilaria chlamydosauri (Breinl) (Nematoda: Filarioidea). Parasitology. 1953, 43, I-3.

MACKerRas J. M. : Filarial Parasites (Nematoda : Filarioidea) of Australian animals. Austr. J. Zool. 1962, $10,400-457$.

Maclean G. S., Lee A. K., Wilson K. J. : A simple method of obtaining blood from lizards. Copeia, 1973, 338-339.

Prod'hon J., BaIn O. : Développement larvaire chez Anopheles stephensi d'Oswaldofilaria bacillaris, filaire de Caïman sud-américain, et redescription des adultes. Ann. Parasitol. Hum. Comp. I972, 47, 745-758.

Sonın M. D., BARUš V : Filariid nematodes in birds and reptiles of Cuba. Folia parasitol., Praha. $1968, I 5,55-65$.

Travassos L. : Sôbre os filarideos do crocodillos sul-americanos. Mem. Inst. Oswaldo Cruz. I933, 27 . I 59-I64. 